Marquette University

e-Publications@Marquette

College of Nursing Faculty Research and

Publications

Nursing, College of

$1-1-2000$

\title{
Through the Eye of the Beholder: Multiple Perspectives on Quality in Women's Health Care
}

Jaynelle F. Stichler

The Stichler Group, Inc.

Marianne E. Weiss

Marquette University, marianne.weiss@marquette.edu

Accepted version. Quality Management in Health Care, Vol. 8, No. 4 (2000): 1-13. Permalink. (C) 2000 Lippincott Williams \& Wilkins, Inc. Used with permission. 


\title{
Through the Eye of the Beholder: Multiple Perspectives on Quality in Women's Health Care
}

\author{
Authors: Jaynelle F. Stichler and Marianne E. Weiss
}

Abstract: Quality is an illusive concept with different meanings to different people. Providers often define quality in terms of patient outcomes, professional standards of practice, predetermined criteria used to measure quality, and even subjective opinion. Patients describe quality in terms of the interpersonal aspects of care, how well they were treated, and the responsiveness of the provider to their needs. This qualitative study using a semi-structured interview defined quality from the perspectives of patients, physicians, nurses, and payers associated with a hospital-based women's service line, and how the attributes of quality varied among the multiple groups. The study also described how stakeholders become aware of quality and how they determined a hospital's quality. From the findings of the study, a conceptual framework of quality in women's health was developed.

As health care organizations strive to create a unique identity within today's competitive arena, quality has emerged as a focal point for organizational identity. Quality and its continual improvement has become the guiding framework for organizational planning and evaluation. Nowhere is competition for services and service line development more intense than in women's services. Health care lenders recognize the power of women as health care consumers who make many of the decisions about the family's health care plan or where the family will receive care. Women often shop around for quality health care services for themselves and their families. They relate stories about the quality of care they have received to others in their network of friends and family.

Quality is an illusive concept. There are many approaches to defining quality, including: (1) a transcendent approach where quality is undefined but evident when it exists; (2) a productbased approach where the product is measured by the quantity of its component attributes; (3) a user-based approach where the measure of quality is its ability to satisfy the customer; (4) a manufacturing-based approach where quality is conformance to standards; and (5) a valuebased approach where quality is excellence at an affordable price. ${ }^{1}$

Many authors have described attributes of quality and suggested strategies for measurement. However, many of these definitions are limited in scope to the specific 
stakeholder group. Increasingly, the multidimensionality and subjectivity in definitions of quality is being recognized and valued. Quality is defined through the eye of the beholder. ${ }^{2}$ Consumers focus on the satisfaction dimension. Professionals focus on treatment outcomes. ${ }^{3}$ Studies of perceptions of quality treat the patient or health care customer as a homogeneous group when, in fact it is not. ${ }^{4}$

Attributes of quality as perceived by women have not been systematically investigated and reported. With increasing recognition of the unique health care needs of women and the woman's role as the family's health care decision-maker, there is a need to define quality from the multiple perspectives of the stakeholders in women's health, i.e., the woman patient, women's health physicians and nurses, and payers. ${ }^{5}$

The purpose of this study was to identify definitions of quality in women's health care from the multiple stakeholders of the women's service line. Listening to the voice of women and their providers provided the foundation for uncovering the way women describe and evaluate quality in their health care services.

\section{Background}

Health care organizations expend substantial resources to measure, monitor, and improve quality. Quality of care has two major components: (1) quality of technical care, and (2) quality of interpersonal care. A third element may be amenities or properties of the care environment. These elements of quality can be assessed through assessment of structure, process, and outcome. ${ }^{6}$ Technical care or product quality refers to the application of professional knowledge to benefit a patient's health while minimizing risks. Interpersonal care or service quality includes the patient-provider relationship and the environmental aspects of care. ${ }^{7}$

Professionals and consumers have differing perceptions about quality. The professional community defines quality by objective, scientific, standard-based criteria. Professional practice guidelines provide standards to ensure the delivery of high quality care ${ }^{8}$ and to compare professional practices of individual providers. There is a considerable body of literature on the consumer's perspective on quality. Patients often assess quality of care by focusing on access, interpersonal aspects of care, how well they are treated, and the success of their treatment. ${ }^{3,8}$ Lynn and Moore ${ }^{7}$ described professional demeanor ("treats me like an individual"), mindfulness, and responsiveness as dimensions of the patients' perception of quality care.

Nurses' perceptions of quality care are based on nurse-patient relationship, collaborative teamwork, and a work environment with resources and support for nurses in their patient care role. Dimensions of the nurse's perception of quality care include: developing a relationship, 
therapeutics (supportive and nurturing care, and nursing care using a scientific approach), unit collaboration, environment/resources. ${ }^{7}$ In a study by Hogston, ${ }^{9}$ nurses identified elements of structure, process, and outcome in qualitative responses to questions about their perceptions of quality. Elements of structure included skill mix, staffing levels, time, and workload. Values and beliefs, being competent, multidisciplinary teamwork, team dynamics, and holistic care were elements of process found in the responses of nurses in this study. Patient satisfaction and meeting patients' needs were outcome elements. In a study conducted by the Rhode Island Department ofHealth, ${ }^{3} 65 \%$ of nurses believed that quality of care in a hospital means treating patients well and paying attention to their personal needs. These nurses attributed differences in quality to staffing levels, training, and experience.

Carson et al. ${ }^{10}$ described the differences in how professionals and patients view quality. Professionals view quality as "doing things right" focusing on treatment efficacy and appropriateness and "as doing things well," focusing on treatment availability, timeliness, continuity, safety, and efficiency. Patients assess quality of health care services by forming impressions of caring, professionalism, competence, and organization. Factors contributing to the perception of quality hospital care include: physicians respect the patient's preferences, well-coordinated care communication of information about long-term effects of illness, pain relief, emotional support involvement of family and friends in decisions, and preparation for discharge. Ten factors contributed to perception of service delivery: (1) tangible (appearance of environment and employees), (2) reliability/dependability of service delivery, (3) responsiveness, (4) competence, (5) understanding the patient, (6) access, (7) courtesy, (8) communication, (9) credibility, and (10) security

There are several conceptual and methodological problems in assessing consumer perspectives on quality health care. ${ }^{11}$ Consumers are often given satisfaction surveys to measure quality and they often view quality of care and quality of services as distinct issues (e.g., food, parking, etc.). Satisfaction and quality are not synonymous. Issues that are important to quality of care such as being treated with respect and being involved in treatment decisions are often not included in satisfaction surveys. Consumers view their health care as a continuum not a single episode. Their perceptions of quality develop and are refined over the longitudinal course of care and services. Health care consumers use personal experience as well as information provided by hospitals, media, and public sources to shape their perception of quality. In one study, $84 \%$ of consumers were interested in receiving information about the quality of care a hospital provides. They wanted to see success rates with treatments, the experience of physicians, and patient satisfaction rates. ${ }^{3}$

\section{Stichler \& Weiss}


The knowledge that quality is multidimensional and specific to each stakeholder group creates the imperative to discover the dynamics of quality within care delivery organizations that have unique patient-provider characteristics. Women's health care brings together women with their unique perspectives and health needs, providers who provide woman-sensitive care, and payers who purchase and manage payments for women's care. Understanding the unique and common dimensions of quality across the stakeholders in women's health care will provide a foundation for development of quality women's health care programs and services.

\section{Methods}

The specific objectives of the study were to:

1. Define quality from the perspectives of patients, physicians, nurses, and payer associated with a hospital-based women's service line;

2. Identify how these stakeholders of a hospital-based women's health service line become aware of quality;

3. Determine how stakeholders of a women's health service line evaluate a hospital's quality; and

4. Compare and contrast how attributes of quality vary across the multiple perspectives of stakeholders of a women's service line.

A qualitative methodology using a semi-structured interview was selected to generate data about perspectives on quality. The study was conducted in a high-volume, tertiary women's hospital in the Western United States and all subjects were directly or indirectly related to the women's service line. The convenience sample consisted of 39 female patients, 23 physicians, 27 nurses, and 19 payer representatives. The patient group included women receiving health services in a variety of settings within a hospital-based women's service line, including ambulatory centers, inpatient postpartum and surgical units, and women's health classes. The physician group included male and female physician providers who provided services within the women's service line. The nurse group consisted of nurses employed in positions within the women's service line. The payer group included representation from self-insured companies, $\mathrm{HMO}$, managed care, and other third-party payers who contract with the hospital for women's services.

Interview teams assigned to each population in the study (patients, physicians, nurses, payers) developed interview questions based on the objectives of the study. The interview teams consisted of nurse managers, clinical nurses, nurse researchers, and market researchers. Once the interview questions were developed, the interviewers were trained in interview 
techniques and participated in mock interviews in preparation for data collection. Each of the interviews were taped and then transcribed.

Content analysis of interview transcripts was conducted by three nurse researchers, with at least two researchers reviewing and coding each transcript. Content, categories and emerging themes were identified and consensus was reached in areas of divergent coding. Summaries of results were presented to nurse and physician groups for validation of themes. Results of the four subject groups were then analyzed for common themes across the multiple perspectives. A model representing the shared perspectives was developed.

\section{Results}

\section{Patients' Perception of Quality}

\section{Attributes of Quality}

Five themes emerged in patients' definitions of quality: (1) competent staff, (2) personalized caring, (3) timeliness, (4) environment/facilities, and (5) organizational characteristics.

Competent staff. Patient respondents indicated that a competent staff who display a strong professional demeanor is essential to quality. Competent staff demonstrate technical skill, assure accuracy in diagnoses, diagnostics tests, and provide effective treatments. The competence of the staff lead to the achievement of expected results, which was perceived by the patients as essential to quality.

Personalized caring. Patients stated that personalized caring was critical to the achievement of quality. This category was characterized by a staff who "take a personal interest in me," "treat me right," and are generally friendly and helpful. Staff who were attentive, anticipatory, and responsive to the patient were essential to the achievement of quality.

Timeliness. Patients defined a sense of timeliness as essential to quality. An attitude of responding in a timely manner to patient requests, efficiency within the patient care environment, and an obvious flow and organization to the work were critical elements of quality. The desire to "be ready" and to keep things moving on schedule added to the sense of timeliness.

Environment/facilities. Patients felt that an environment that appeared to be clean and comfortable were essential to quality. Comfort was described as including "no smoking policies," privacy for the patient, and an environment that was familiar and home-like. Other elements of quality within the environment and facilities related to attention to the quality of the food, availability of security in the hospital environment and grounds, and availability of parking.

\section{Stichler \& Weiss}


Organizational characteristics. Organizations that were perceived as "strong and growing" and that offered multiple types of services to the patient were perceived to have quality.

\section{Evaluating Quality}

Patients described several ways in which they evaluated the quality of hospitals. Key sources of information included their own personal experience within the hospital or with programs associated with the hospital. Another key source of information related to recommendations by their own physician or the experiences of family, friends, or co-workers.

Secondary sources of information that patients used to evaluate quality included personal observations of the hospital that may have occurred on tours, the overall reputation of the hospital within the community, and their interface with consumer outreach education, seminars, and services. Direct mail, newspaper ads, billboards, and radio and TV advertisements were cited as ways that patients learned about the hospital and its programs, but they did not necessarily use these methods to assess quality.

\section{Choosing a Hospital}

Patients indicated that they were influenced primarily by their own insurance or health plan in choosing a hospital, and secondarily by their physician. (It should be noted, however, that the study was conducted in a highly managed care community where the contract limits the selection of hospitals and providers.) Patients indicated that the location and access to the hospital, size, appearance, and accommodations within the hospital setting were also important secondary factors. The reputation of the hospital in providing care in a patient-focused manner and its scope of services were also factors that contributed to choice of hospital.

\section{Physicians' Perception of Quality}

\section{Attributes of Quality}

Several recurrent themes were identified when physicians were asked to define quality and describe the important characteristics of quality. Four categories were identified: (1) professional competence, (2) outcomes, (3) scope of services, and (4) the caring environment. Professional competence. Physicians indicated that professional competence was an extremely important characteristic of quality. The requisite for competence extended beyond the medical staff to nurses and other support departments, such as radiology, laboratory, etc. Accuracy of patient assessment and diagnostic information were indicators of quality. Competence also pertains to systems within the organization to ensure professional competence, such as compliance with recognized standards of care and monitoring for appropriateness of care.

Competence of nursing staff was described in terms of the nurse's knowledge. When physicians were asked how they would know that nurses were giving quality care, three themes 
emerged: (1) how the nurse communicated; (2) the nurse's skill, competence, and knowledge; and (3) the judgment of the nurse. How the nurse communicated with the physician was an important indicator of how the physician perceived the quality of nursing care. Descriptors of how the nurse communicated or how the physician viewed the nurse's interpersonal skills in communicating with the physician included the nurse's helpfulness, anticipation of the physician and patient needs, professional demeanor, and friendliness. The physicians indicated that there should be purposefulness in the nurse's communication to the physician, characterized by confidence, anticipation, eagerness, and a desire to learn. Generally, the communication reflected an interest in both the patient and the physician.

The nurse's skill, competence, and knowledge level, or "what" the nurse communicated was described as the nurse's accurate assessment of the patient's needs or condition and pertinent information that were imparted to the physician. This information demonstrated her/his current clinical knowledge. In addition, the technical knowledge of the equipment, as well as the current knowledge of clinical subject matter, were described as two important indicators of nursing care quality.

The judgment of the nurse was a critical indicator of quality nursing care and was characterized by nurses identifying pertinent problems, asking appropriate questions, coming to appropriate conclusions, and knowing when to communicate these findings to the physician and others.

Outcomes. The outcome category included the patient's perception of their hospital care including their satisfaction level and their perceptions that their expectations were met. It was often described as the patient having a good experience in the hospital in spite of the diagnostic outcome. The physician's perception of the patient's outcome was also an indicator of quality. Scope of services. The scope of services was described by physicians as "state of the art" technology and the availability of diagnostic and treatment services to support a comprehensive scope of services.

Caring environment. The category of "caring environment" included several attributes that the physicians related to quality. They suggested that the interactions between team members in caring for the patient was essential to quality. Efficiencies within the environment enabling the physician to get his or her work done quickly and to prevent redundancy, error, or rework was also a characteristic and was valued by physicians as essential to quality care. The cleanliness of the environment was specifically identified as an attribute of quality. Another attribute of the caring environment included a sense of time, including the sensitivity to the physician's time 
while making rounds in the hospital and a timely response by other care providers to the physician's need for assistance and information.

\section{Learning About Quality}

Physicians identified five themes when asked how they initially learned about the quality of a hospital: (1) reputation of the hospital, (2) physician to physician contact, (3) patient feedback, (4) personal experience, and (5) information from professional organizations.

According to physicians in this study, the reputation of the hospital was influenced by the hospital's affiliations with other hospitals and health care providers, the types of physicians on staff, and hospital supports to the physician for continuing medical education, business development, library services and research support, and diagnostic support services.

Physicians used other physicians to learn about the quality of a hospital, as well as their own personal experiences as physicians on staff. Word of mouth or other physicians sharing their impressions of quality were frequently listed as a resource to not only learn about quality but also to continually evaluate quality over time. Equally important was feedback from their patients about the quality of the care and services that the patient or their family members had received. Physicians indicated that they generally do not use television, radio, newspaper, hospital newsletters, or information from other physicians to evaluate quality, but they frequently use these sources to learn more about the institution and quality related issues. The hospital's provision of medical education and a hospital newsletter that promotes new and innovative programs, research findings, and outcome measures were listed as ways that physicians learn about quality.

\section{Evaluating Quality}

Five themes emerged when physicians were asked how they evaluate quality of a hospital over time. These themes included: (1) formal processes, (2) observation and experiences, (3) patient feedback, (4) educational offerings, and (5) hospital-sponsored activities.

Formal processes cited included hospital committee work where patient outcomes were discussed for utilization review, peer review, or quality assurance. Outcome statistics and other quality measures were used to formulate opinions about the level of quality within the hospital.

Physicians compare and evaluate the quality of hospitals through personal experience by direct observation of patient care and solicited and unsolicited feedback from the patient. By observing the operational efficiencies within the hospital, including staffing, scheduling, and "getting things done on time," the physicians were able to evaluate quality of care. Physicians frequently cited their comparison of nursing staff satisfaction, adequate staffing levels, as well

\section{Stichler \& Weiss}


as competence among hospitals stating that a satisfied staff contributes to quality care. The overall climate of the hospital was also cited as a way that physicians evaluate quality over time. Perceptible elements of organizational climate included staff morale, satisfaction, and responsiveness in assisting the patient, each other, and the physician. The availability of resources and services to provide support to the physician, including access to state of the art equipment and operational efficiencies in managing the physician's time, were frequently compared across hospitals in the community.

Informal evaluation was conducted on a continual basis by physicians sharing personal experiences with one another in informal group settings such as physician dining rooms and lounges. This informal method which physicians referred to as "word of mouth or gossip" should not be underestimated since this process occurs on a regular and daily basis resulting in ongoing reevaluation of the physician's perception of quality.

Physicians' opinions of quality were influenced by reports of innovative programs and services, research results, new approaches to medical care, and other communications of "'state of the art" developments provided in hospital publications, conferences, or other educational events. Physicians verbalized that the hospitals that provided continuing medical education or other educational resources were considered to be the "top quality" hospitals. Hospital-sponsored activities that demonstrated a commitment to the professional community such as dinners, galas, or sports events were also cited as characteristics of quality hospitals.

\section{Nurses' Perception of Quality}

Attributes of Quality

Nurses described five characteristics of quality including: (1) patient outcomes, (2) caring, (3) time, (4) nursing process, (5) systems support.

Patient outcomes. Nurses reported that patients' satisfaction with their care and appropriate management of their care were essential to quality. They suggested that sending the patient home in an appropriate time frame and in an improved health status were important characteristics of quality. The improved health status was not always described as "wellness" but also reflected the patient's adaptation to illness and preparation for self or home care. Caring. Nurse participants considered caring to be an essential characteristic of quality. They defined caring as "care that related to the total person and his/her specific needs rather than to standardized or routine care. Meeting the patient's and family's specific needs" in a manner that reflected a caring attitude exemplified by nurturing, concern, sensitivity, active listening, and friendliness summarized the descriptors of quality presented by the nurses interviewed for the study.

\section{Stichler \& Weiss}


Time. Time was a critical factor in the nurses' perception of quality. This characteristic was described as "time to listen to the patient," "time to do for the patient," a sense of efficiency in terms of work flow, organization, and continuity rather than fragmentation of patient care. Many nurses verbalized that the 12-hour shift was one means in which continuity of patient care provided a quality element.

Nursing process. The nursing process, as a critical element of quality, was characterized as the nurse's anticipation and prevention of patient problems and the nurse's ability to give good care, which led to discussions of elements of professional competence, continuing education for the nursing staff, and appropriate staffing. The foundation for practice such as nursing standards, policies and procedures, theory-based practice, and nursing research were cited as essential elements of quality. Other elements of quality were described as "a sense of camaraderie and teamwork" among nurses, coordination of patient care with other hospital caregivers, and effective and compassionate communication with the patient, which served to comfort as well as educate and inform.

System support. Nurses also cited systems support as critical to quality and articulated the importance of administrative support and an organizational mission and philosophy that promoted quality as a framework for care delivery. Resource availability and positive interdepartmental relationships were described as elements of system support and were cited as important to quality.

\section{Learning About Quality}

Nurses initially learn about quality through site visits, personal networks, professional sources, media and advertising, and work experience. The nurse respondents stated that a site visit with a tour of the hospital, an interview with the nurse recruiter or nurse manager, talking with staff and personal observation within the hospital environment assisted them in initially learning about quality. Their personal network of friends, patients, and physicians also gave them valuable information to initially learn about quality.

Publications within professional journals, presentations by hospital staff, local and national conferences, and involvement in professional organizations assisted nurses in initially learning about the quality of a hospital. Hospitals that had employees who participated in publishing and presenting were considered to be quality hospitals. While nurses indicated that they did not necessarily use newspapers, television, community education programs, or billboards to learn about the quality of a hospital, these promotional activities certainly assisted in acquainting them with the hospital. Most importantly the personal experience of working within the hospital helped the nurse to learn about the quality of the hospital and many nurses 
related that they purposely worked for an outside registry before making a commitment to a hospital in order to compare several hospitals.

\section{Evaluating Quality}

Five categories of responses characterized how nurses evaluate quality, including (1) patient services, (2) organizational characteristics, (3) nursing services, (4) nursing staff, and (5) physicians.

In evaluating quality, nurse respondents indicated that the acuity level of patients within the hospital as well as populations served by the hospital reflected the quality of care provided by a hospital. When asked to clarify these opinions, these respondents indicated that hospitals that deliver high acuity care and are not inundated with indigent populations, gave better quality care. Hospitals that were able to provide a full scope of services to the patient and characteristically had a high occupancy were also considered quality hospitals. Nurses were also interested in statistics relating to patient services including morbidity and mortality rates, infection rates, and other indicators of patient outcomes. Hospitals that embraced a philosophy of consumer or family-focused care were considered to be quality hospitals.

In describing quality hospitals, nurses in the study indicated that they evaluated the management philosophy and looked for elements of employee participation and staff empowerment, commitment to quality, stability, and evidence that nurses were valued within the organization. The hospital's overall image and reputation in the community certainly influences their evaluation of quality. Hospitals that demonstrated administrative support and valuing of nurses with education incentives, appropriate pay and benefits, and recognition for staff performance were also considered to be quality hospitals. Other indicators of quality included the hospital's accreditation with regulatory agencies, safety records, and overall financial stability.

In evaluating a hospital's quality, nurses indicated that nursing services would be patientoriented with adequate nurse-to-patient ratios and appropriate use of ancillary staff to support nursing care. The nursing service in quality hospitals would be "pro-nursing," encouraging staff empowerment models, supporting staff education, and encouraging and facilitating nursing research. Additionally, these hospitals would have nursing management who were easily accessible, receptive, and open to new ideas and discussion.

Nursing staff within quality hospitals was described as competent, motivated to grow professionally, and demonstrating a pride in professionalism. Additionally, these staff were characterized as "happy with their jobs," courteous, responsive, and demonstrating camaraderie, high morale, and staff unity. Staff in quality hospitals were described as those who "felt

\section{Stichler \& Weiss}


appreciated by physicians, management and their patients" and were able to work in an environment that was sensitive to their stress levels. In evaluating quality, nurses indicated that they assessed the availability, approachability, and accessibility of physicians. Physicians in quality hospitals were cited as those who "treated nurses as partner in care," trusting, and exemplified a professional bedside manner.

The physical and aesthetic environment was a dimension that nurses evaluated in their assessment of quality. Quality hospitals were described as clean, organized, and uncluttered in appearance. These hospitals gave attention to aesthetics and to the quality of food, the amenities offered to patients, and the noise level within the environment. Generally, quality hospitals were those that sought to create a positive internal image for the staff and patients. "Payer's" Perceptions of Quality

Managed care providers, third party payers, and large employers who contract directly with providers for health care services are becoming increasingly interested in quality assessment. One respondent indicated that "I went to a conference of Fortune 500 companies and every single speaker mentioned total quality management. I see it as the next level of competition among hospitals. Large employer groups are now insisting on it." This view is replacing a former attitude of "if they are accredited, we assume care is okay."

\section{Criteria for Selecting Quality Hospitals}

The payer respondents cited five categories that reflected how they selected quality hospitals, including: (1) regulatory agency accreditation, (2) image, (3) scope of services, (4) appropriateness and quality monitoring, and (5) organizational characteristics.

Regulatory agency accreditation. Payers gave credence to evaluating whether or not hospitals were accredited by the Joint Commission on Accreditation of Healthcare Organizations (the Joint Commission), state licensing agencies, and Medicare. Without these accreditations, payers were less likely to think of the hospital as a quality hospital.

Image. The hospital's overall reputation and image in the community were critical as elements of quality. The "look of the hospital" and its cleanliness were also cited as important to the quality perception.

Scope of services. Payers were interested in selecting hospitals that offered a full array of services and experience with specialized procedures. This category was so important in evaluating quality that many payers indicated that they actually require experience in a specified number of cases in order to consider the hospital as qualified in particular specialty areas, for example, coronary artery bypass surgery. 
Appropriateness of quality monitoring. Measures of appropriateness of care and evidence of quality monitoring were used by payers in evaluating quality of hospitals. Infection rates, pending litigation, Medicare denial rates, and medical quality assurance board actions were all methods that were used to evaluate the quality within a hospital. Additionally, active quality assurance, quality improvement, and utilization review programs were important to the perception of quality.

Organizational characteristics. Payers were most influenced by interactions with the hospital's business offices and assess quality based on these interactions. They also indicated that the overall performance of the staff, patient feedback and satisfaction, and employee opinions of the hospitals were elements that influenced their perception of quality. The nurse-to-patient ratio was frequently assessed as a measure of quality. Another element that was important to payers in assessing quality was in the location and accessibility of the hospital for patient convenience. The hospital's liability coverage was also assessed during review of quality.

\section{Learning about Quality}

Many managed care plans and third-party payers have well-defined quality standards for various service lines such as cardiac, transplant, burn, and psychiatric care, but these standards were not as well defined for women's and maternity services. The respondents indicated that they were beginning to review several indicators reflecting quality including cesarean section rates, percentage of vaginal birth after cesarean section, prematurity rates, re-admission rates, return to OR rates, complications, patient complaints, infection rates and wound infections, and average length of stay. Evidence of discharge planning and referrals to home health were also indicative of quality as well as specific practice patterns that reflected contemporary practice. Sources of Information on Quality

Payers indicated that they survey their constituents regarding the quality of care rendered by specific hospitals, and are interested in identifying any problems that the patient may have encountered. Payers had many approaches to surveying their plan members, including random sampling, annual sampling of all members, sporadic sampling, and in some organizations, with every hospital encounter. Other sources of information included Medicare length of stay and cost reports and investigation of quality elements during the contracting process.

Feedback from these surveys and assessments of patient responses to hospital care yielded several frequent problems leading to patient dissatisfaction and cited examples of "employees with a non-caring attitude," a dirty and unkempt appearance within the hospital, and unexplained and unattended waiting periods in ancillary departments. Dissatisfaction with the

\section{Stichler \& Weiss}


billing process was frequently cited. Treatment outcomes had the potential to affect perception of quality. Patients who had to be readmitted to the hospital or who had questionable treatment while in the hospital frequently had negative reports of quality. Surgery delays, surgery complications, and unexpected delays in treatment also contributed to negative impressions of quality.

Lack of discharge planning that contributed to under- and overutilization of services and extended lengths of stay were critically reviewed by payers as indicators of poor quality.

Awareness of the guidelines for length of stay by diagnoses and collaboration between hospital personnel and the payer company were cited as evidence of quality. Problems with the billing process, poor interaction between the billing office and the payer office, and excessively high and unexplained charges gave negative impressions of quality.

\section{Quality across the Multiple Perspectives}

Following analysis of the data for each of the subject groups, a further level of analysis across the multiple perspectives resulted in identification of eight key attributes of quality in women's health care: (1) patient outcomes, (2) caring environment and attitude, (3) professional competence, (4) time sensitivity, (5) professional relationships, (6) scope of services, (7) environment, and (8) support systems (see Table 1).

While these dimensions cross the multiple stakeholders of women's health care, their descriptors are unique within each stakeholder group.

Final synthesis and integration of the data yielded a model of three universal dimensions that were represented in the responses of all four subject groups. These three dimensions included personal interactions characterized by personal valuing, professional demeanor, coordinated team work, and staff attitudes and morale; system effectiveness characterized by valuing time, adequate staffing, comprehensive-services, availability of resources, and an aesthetic environment; and competence characterized by technical skills of the professional staff, accuracy of diagnosis and treatment, compliance with standards of care, credentialing by regulatory agencies, and continuing professional education. The interaction of these three dimensions impacts the quality of patient health outcomes and satisfaction with care and services (see Figure 1).

\section{Discussion}

Dimensions of quality described by patients, providers, and payers are consistent with dimensions described by others. For all stakeholders, personalized caring reflected a recognition of the unique interaction needs of women. Women want and expect competence in 
their providers and evaluate this competence based on personal interactions. System effectiveness, evidenced by sensitivity to time management reflect the complexity of contemporary women's lives. Aesthetics was an important issue for women consumers. While each stakeholder group identified dimensions of quality from their unique perspective, there were common themes that emerged across the dimensions. Building on these common definitions will provide a basis for a synergistic effort to develop quality in women's health care.

The results of this study are intended to inform those involved in the design and delivery of women's health care services about the unique perspectives on quality of women, their providers, and payers. Previous studies have approached definitions of quality from consumers' and providers' perspectives, but without the focus on gender specific perspectives. From this study, we have begun to illuminate women's perspectives on quality of care.

The key elements cited by the respondents in this study can be used in the development of quality indicators for measurement and improvement of women's health care. Examples cited from this study can be used to increase provider awareness of quality indicators from the customer's perspective. The findings of this study have implications for professional practice of both nursing and medicine and in the administration of health care services within the hospital environment. The findings can also influence quality improvement and assist in contract negotiations with third-party payers.

No attempt has been made to make any comments or comparisons with responses that may be similar and different in terms of men's perspectives on quality. In addition, the respondents ill this study were all associated with a tertiary level medical center with an existing women's service line. Expectations may be different in smaller institutions or those without a defined focus on women's health care. Further research is needed on perceptions of quality in organizations of varying size and geographic area and with male patients and their providers to determine if the dimensions and definitions of quality as identified in this study are specific to the women's perspective or if they can be more universally applied.

\section{Conclusion}

Unique aspects of quality from the perspectives of women patients and their providers and payers have been described. A synthesis and integration of these perspectives resulted in the development of eight common dimensions of quality and a model for quality of women's health care services.

\section{Notes}

15 Stichler \& Weiss 
- Jaynelle F. Stichler, DNSc, Principal, The Stichler Group, Inc., San Diego, California

- Marianne E. Weiss, DNSc, RN, Associate Professor of Nursing, Marquette University, College of Nursing, Milwaukee, Wisconsin

\section{References}

1. D.A. Garvin, Managing Quality: The Strategic and Competitive Edge. (New York: The Free Press, 1988.)

2. J. S. Gonen, "Quality in Women's Health: Taking the Measure of Managed Care," Jacobs Institute Insights July 1998): 1-8.

3. Rhode Island Department of Health, Health Care Quality Steering Committee, "Health Care Quality Performance Measurement: Quality Hospital Care: What Does It Mean," http://state.ri.us/quality (Accessed 1999).

4. L.A. Lang and T.E. Shannon, "Patients Perspective: Conference Overview," Journal of Quality Improvement 23, no. 5, (1997): 231-238.

5. National Association of Professionals in Women's Health. "Quality in Women's Health: The National Women's Health Quality Initiative," NAPWH Focus 12, no. 1, (1999): 3-4.

6. A. Donabedian, "The Quality of Care: How Can It Be Assessed?" Journal of the American Medical Association 260, (1988): 1743-1748.

7. M.R. Lynn and K. Moore. "Relationship between Traditional Quality Indicators and Perceptions of Care," Seminars for Nurse Managers 5, no. 4, (1997): 187-193.

8. P.W. Barnes et al, "Standards of Care in Reproductive Health Services," Western Journal of Medicine 163, suppl. (1995): 28-32 .

9. R. Hogston, "Quality Nursing Care: A Qualitative Inquiry," Journal of Advanced Nursing 21, (1995):116-124.

10. P.P. Carson, et al., "Towards Understanding the Patient's Perception of Quality," The HealthCare Supervisor 16, no. 3 (1998):36-42 .

11. P.D. Cleary and S. Edgman-Levitan, (1997). "Health Care Quality: Incorporating Consumer Perspective," Journal of the American Medical Association 278, (1997): 16081612. 


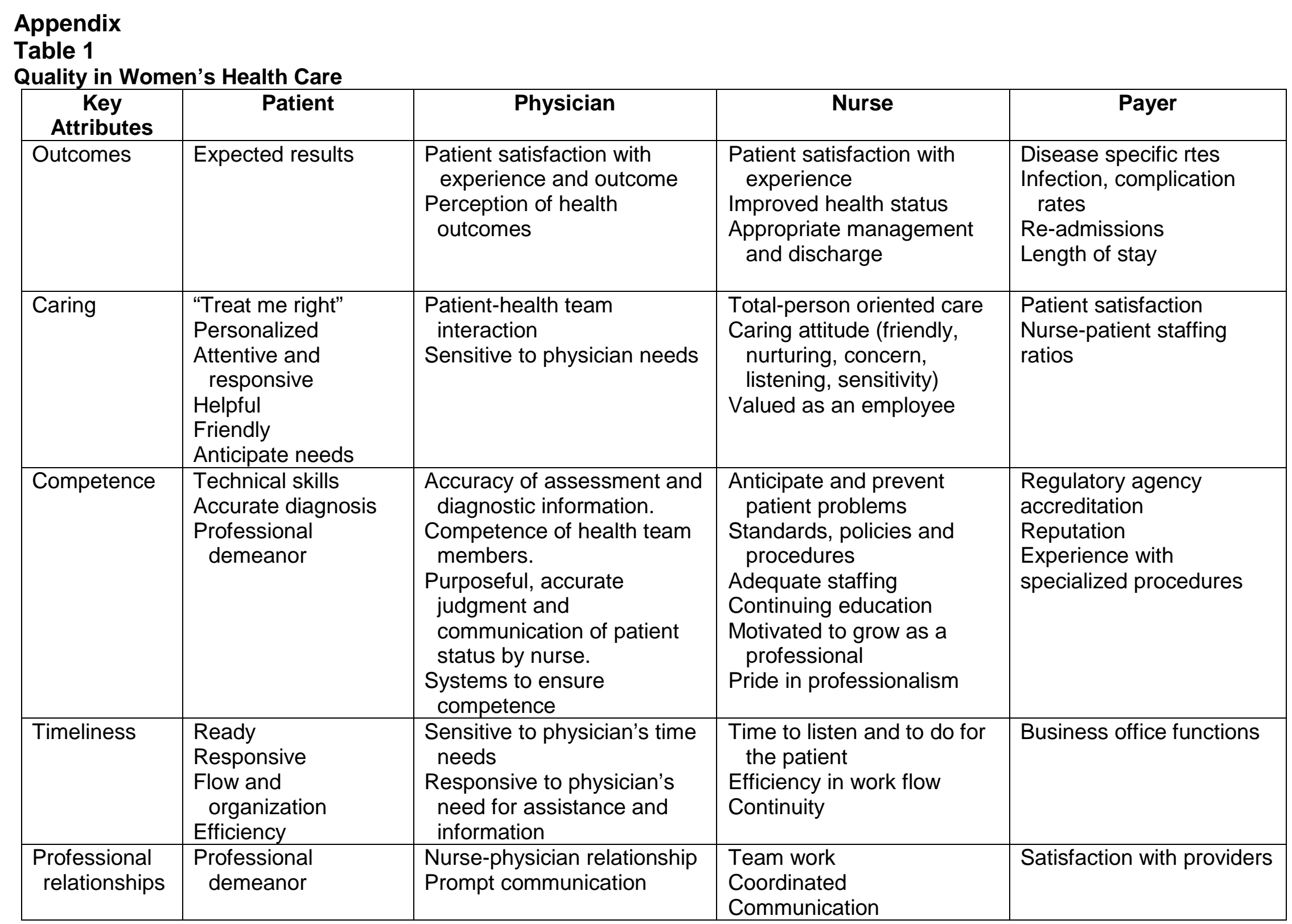

17 Stichler \& Weiss 


\begin{tabular}{|l|l|l|l|l|}
\hline $\begin{array}{l}\text { Scope of } \\
\text { services }\end{array}$ & $\begin{array}{l}\text { Multiple types of } \\
\text { services } \\
\text { Strong, growing } \\
\text { organization }\end{array}$ & Full, comprehensive services & $\begin{array}{l}\text { Full scope of services } \\
\text { Customer, family oriented }\end{array}$ & Full scope of services \\
\hline Environment & $\begin{array}{l}\text { Clean } \\
\text { Aesthetic } \\
\text { Comfort } \\
\text { Privacy } \\
\text { Security }\end{array}$ & $\begin{array}{l}\text { Organizational climate } \\
\text { Staff satisfaction and morale } \\
\text { Adequate staffing }\end{array}$ & $\begin{array}{l}\text { Clean } \\
\text { Aesthetic } \\
\text { Organized } \\
\text { Staff morale }\end{array}$ & $\begin{array}{l}\text { Clean } \\
\text { "Look of the hospital" }\end{array}$ \\
\hline $\begin{array}{l}\text { Support } \\
\text { systems }\end{array}$ & Technology & $\begin{array}{l}\text { Administrative support } \\
\text { Mission and philosophy } \\
\text { Resource availability }\end{array}$ & $\begin{array}{l}\text { Active quality assurance, } \\
\text { quality improvement, and } \\
\text { utilization review } \\
\text { programs }\end{array}$ \\
\hline
\end{tabular}


Figure 1

Quality Framework for Women's Health Care
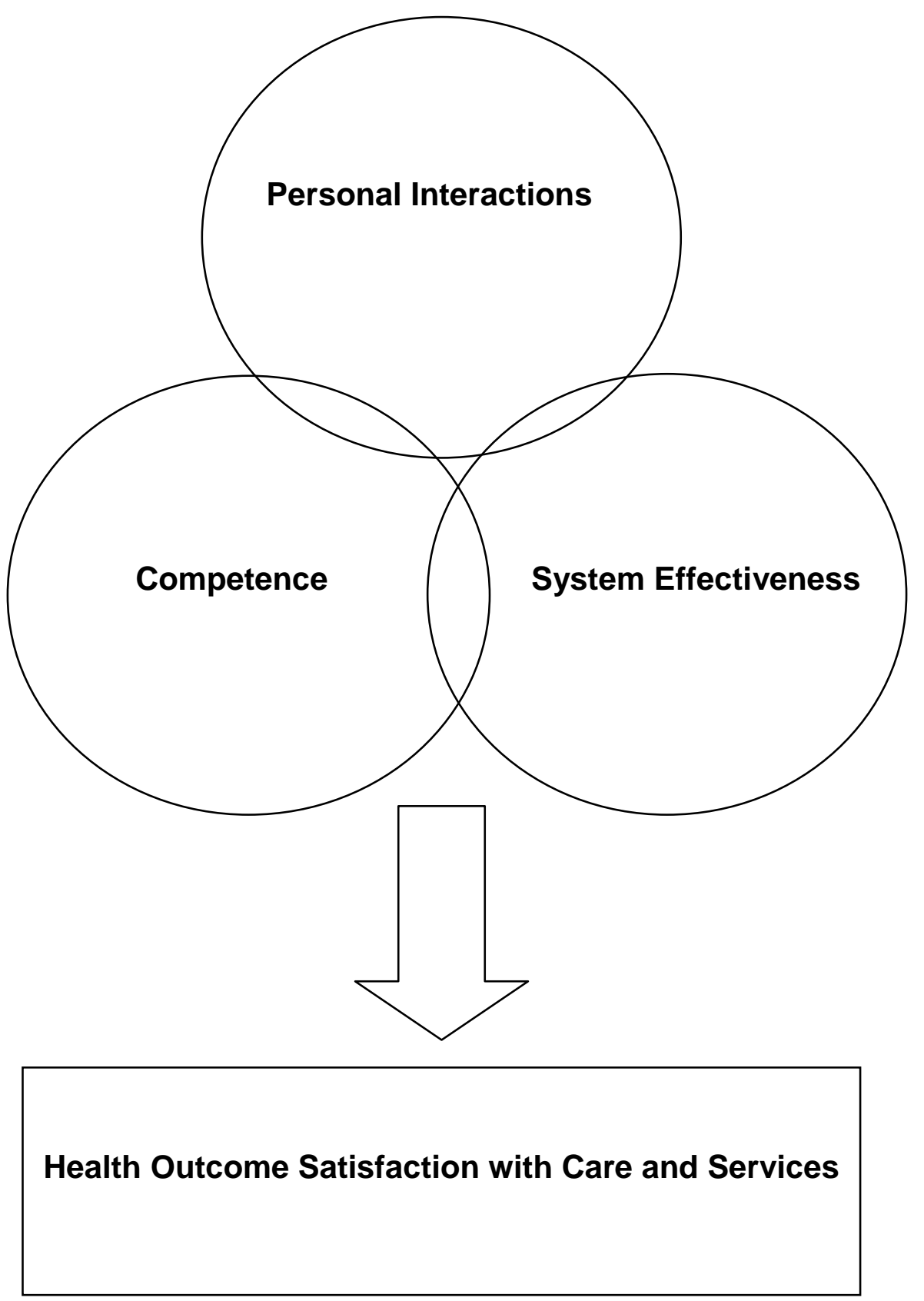

19 Stichler \& Weiss 